\title{
Prenatal exposure to maternal undernutrition induces adult cardiac dysfunction
}

\author{
Kuljeet K. Cheema ${ }^{1}$, Melissa R. Dent ${ }^{1,2}$, Harjot K. Saini ${ }^{2}$, Nina Aroutiounova ${ }^{1}$ and Paramjit S. Tappia ${ }^{1}$ \\ ${ }^{1}$ Institute of Cardiovascular Sciences, St. Boniface Hospital Research Centre \& Department of Human Nutritional Sciences, \\ Faculty of Human Ecology, University of Manitoba, Winnipeg, 351 Tache Avenue, Winnipeg, Manitoba, Canada R2H $2 A 6$ \\ ${ }^{2}$ Institute of Cardiovascular Sciences, St. Boniface Hospital Research Centre \& Department of Physiology, Faculty of Medicine, \\ University of Manitoba, 351 Tache Avenue, Winnipeg, Manitoba, Canada R2H 2 A6
}

(Received 12 July 2004 - Revised 1 December 2004 - Accepted 6 December 2004)

\begin{abstract}
An adverse environmental experience of the growing fetus may lead to permanent changes in the structure and function of organs that may predispose the individual to chronic diseases in later life; however, nothing is known about the occurrence and mechanisms of heart failure. We employed a rat model in which pregnant dams were fed diets containing either $180 \mathrm{~g}$ (normal) or $90 \mathrm{~g}$ (low) casein $/ \mathrm{kg}$ for 2 weeks before mating and throughout pregnancy. The ejection fraction (EF) of the pups exposed to the low-protein (LP) diet was severely depressed in the first 2 weeks of life and was associated with an increase in cardiomyocyte apoptosis. This early depressed cardiac function was followed by progressive recovery and normalization of the EF of the offspring in the LP group. The left ventricular (LV) internal diameters were increased between $24 \mathrm{~h}$ and $84 \mathrm{~d}$ (12 weeks) of age in the LP-exposed group. Although between $3 \mathrm{~d}$ and 2 weeks of age the LV wall of the heart in the LP group was thinner, a progressive increase in LV wall thickness was seen. At 40 weeks of age, although the EF was normal, a two-fold elevation in LV end-diastolic pressure, reduced cardiac output, decreased maximum rates of contraction and relaxation, and reduced mean arterial pressure were observed. Our findings demonstrate that exposure of the developing fetus to a maternal LP diet programs cardiac dysfunction in the offspring in later life.
\end{abstract}

Low-protein diet: Cardiomyocyte apoptosis: Cardiac hypertrophy: Heart dysfunction

The environmental experience of the growing fetus influences the development of specific organs. An adverse environmental exposure leads to irreversible adaptations in the structure and function of organs that may predispose the individual to the later onset of chronic disease (Barker, 1997). This has been characterized as 'programming', and has been termed the 'Barker hypothesis' or 'the fetal origins hypothesis'. Maternal undernutrition is known to play a role in intrauterine growth retardation (Godfrey et al. 1997) and while earlier epidemiological studies demonstrated a link between low birth weight, poor early growth and risk of CVD (Barker et al. 2002), current evidence suggests also that the size of the mother determines her ability to support protein synthesis and is associated with fetal growth and development (Adair et al. 2001). The extent to which the effect of an adverse environment in utero can be reversed by improved conditions postnatally is not clear, but evidence suggests that 'catch-up' growth imposes its own metabolic stress and may itself exert a harmful effect (Fall et al. 1995; Cianfarani et al. 1999). In fact, it has recently been reported that the life span is shortened considerably if the period of growth is accelerated to make up for reduced growth in utero (Aihie Sayer et al. 2001).

Although it has been reported that growth-retarded fetuses exhibit hypertrophy of both ventricles (Al-Ghazali et al. 1989;
Veille et al. 1993; Vonnahme et al. 2003) as well as haemodynamic dysfunction (Rizzo \& Arduini, 1991; Severi et al. 2000), and that left ventricular (LV) enlargement may be a long-term result of haemodynamic changes in utero (Vijayakumar et al. 1995), virtually nothing is known about the occurrence and mechanisms responsible for cardiac dysfunction in later life. Therefore, by employing a well-established rat model of intrauterine growth retardation (Langley \& Jackson, 1994), the present study was undertaken to examine if a maternal low-protein (LP) diet during pregnancy induced changes in the structure and function of the heart of the developing fetus, predisposing the offspring to cardiac abnormalities in later life.

\section{Materials and methods}

Experimental animals

All experimental protocols for animal studies were approved by the Animal Care Committee of the University of Manitoba, following the guidelines established by the Canadian Council on Animal Care. Ten virgin female Wistar rats $(235-270 \mathrm{~g})$ were housed individually in cages and maintained at $24^{\circ} \mathrm{C}$ on a $12 \mathrm{~h}$ light cycle. The animals were divided into two equal groups and fed ad libitum on isoenergetic synthetic diets containing 
$180 \mathrm{~g}$ (normal) or $90 \mathrm{~g}$ (low) casein/kg (Langley \& Jackson, 1994) for 2 weeks before mating and throughout pregnancy; the animals had free access to water. The composition of the synthetic diets employed in this study is shown in Table 1 . All the dams in the two groups were successfully mated. Within $12 \mathrm{~h}$ of giving birth the mothers were fed standard laboratory chow and remained on this diet throughout the suckling period. No difference in maternal behaviour between the diets was observed. Although the number of pups per litter ranged from eight to fourteen, to prevent artefacts from the possibility of milk insufficiency due to differences in birth number between diets or milk quantity/quality in previously malnourished dams, the litter size was culled to nine across the groups. The pups were weaned at 4 weeks of age on to the chow diet and were housed in pairs. The body weights of all offspring were recorded at birth and up to 40 weeks of age. The cardiac functional assessment was conducted in equal numbers (three) of male offspring chosen at random and distributed between all five pregnancies per diet. Although the range of birth weights was within $\pm 2 \%$ of the mean value, pups were randomly selected for these measurements to avoid any bias and to reflect a representative group of pups within the litters.

\section{Echocardiography of the heart}

An ultrasound imaging system (SONOS 5500 ultrasonograph; Agilent Technologies, Mississauga, ON, Canada) was used for the measurement of cardiac output, heart rate, systolic and diastolic pressures, LV wall size and internal diameters during systole and diastole, and ejection fraction (EF) of the hearts of male offspring exposed to a maternal LP diet. Echocardiographic measurements were conducted in rats anaesthetized using $2.5 \%$ isoflurane in $21 \mathrm{O}_{2} \mathrm{~min}^{-1}$. Briefly, the transthoracic short-axis measurements were performed using a $15-\mathrm{MHz}$ annular array ultrasound transducer for rats up to $21 \mathrm{~d}$ of age and a $12-\mathrm{MHz}$ transducer for rats from 4 to 40 weeks of age. The heart was first imaged in the two-dimensional mode in the parasternal long-axis view. From this view, an M-mode cursor was positioned perpendicular to the interventricular septum and posterior wall of the left ventricle at the level of the papillary muscle and M-mode images were obtained for wall thickness and chamber dimensions (Yang et al. 1999). Images were stored in digital format on a magnetic optical disk for review and analysis.

Table 1. Composition of synthetic diets ( $\mathrm{g} / 100 \mathrm{~g}$ diet)

\begin{tabular}{lcc}
\hline Component & Control & Low protein \\
\hline Casein & 18 & 9 \\
Sucrose & 21.3 & 24.3 \\
Cellulose fibre & 5 & 5 \\
Cornstarch & 42.5 & 48.5 \\
Vitamin mix & 0.5 & 0.5 \\
Mineral mix & 2 & 2 \\
Maize oil & 10 & 10 \\
Choline chloride & 0.2 & 0.2 \\
Methionine & 0.5 & 0.5
\end{tabular}

The raw ingredients were mixed with water $(200 \mathrm{ml} / \mathrm{kg}$ diet) and layered onto trays at approximately $2.5 \mathrm{~cm}$ thickness, dried for $24 \mathrm{~h}$ at $60^{\circ} \mathrm{C}$ and stored in the dark at $-20^{\circ} \mathrm{C}$. The diet was provided to the animals as biscuits $(60-80 \mathrm{~g}$ dry weight). The above compounds were purchased from Harlan Teklad (Madison, WI, USA) with the exception of methionine, which was purchased from Sigma-Aldrich (Oakville, Ontario, Canada). The small differences in macronutrient composition are due an adjustment in the proportion of carbohydrate in the low-protein diet, to ensure that the diets are isoenergetic.

\section{Assessment of cardiac function by in vivo catheterization}

At 40 weeks of age, the male offspring were anaesthetized with an injection of ketamine/xylazine $(1.0 \mathrm{ml} / \mathrm{kg}$ subcutaneously). A micromanometer-tipped catheter (2-0, model SPR-249; Miller Instruments Ltd., Burnabo, BC, Canada) was inserted into the right carotid artery and advanced into the left ventricle. Measurements for LV systolic pressure, LV end-diastolic pressure, rate of contraction $\left(+\mathrm{d} P / \mathrm{d} t_{\max }\right)$, rate of relaxation $\left(-\mathrm{d} P / \mathrm{d} t_{\max }\right)$ and mean arterial pressure were recorded as previously described (Tappia et al. 1999). Pulse pressure was the difference between systolic and diastolic blood pressures. Haemodynamic data were computed and displayed using AcqKnowledge Software (MP System 'Quick Start'; Biopac System, Inc. Goleta, CA, USA).

\section{Neonatal cardiomyocyte isolation}

Primary cultures of male neonatal rat $(24 \mathrm{~h}$ to $14 \mathrm{~d}$ of age) cardiomyocytes were prepared from ventricular tissue, according to the method of Malhotra \& Brosius (1999), by six 15 min digestions at $37^{\circ} \mathrm{C}$ in HEPES-buffered saline containing $740 \mathrm{U}$ collagenase, $370 \mathrm{U}$ trypsin, $2880 \mathrm{U}$ Dnase and $1 \%$ fetal bovine serum. The dissociated cells were collected by centrifugation at $400 \mathrm{~g}$ for $5 \mathrm{~min}$ and re-suspended in buffer (composition, g/l: $6.8 \mathrm{NaCl}, 4.76$ HEPES, 0.138 $\mathrm{NaH}_{2} \mathrm{PO}_{4}, 0.6$ glucose, $0.4 \mathrm{KCl}, 0.205 \mathrm{MgSO}_{4}$, 0.002 phenol red; $\mathrm{pH} 7.4)$. The cells were selectively enriched by differential centrifugation, at $2100 \mathrm{~g}$ for $30 \mathrm{~min}$, through a discontinuous Percoll gradient of densities 1.05, 1.062 and $1.082 \mathrm{~g} / \mathrm{cm}^{3}$. The band at the $1.062 / 1.082$ density interface was collected and used as the source of cardiomyocytes.

\section{Quantification of cardiomyocyte apoptosis}

Cytoplasmic histone-associated DNA fragmentation was quantitatively determined using the Cell Death Detection ELISA ${ }^{\text {PLUS }}$ kit (Roche Applied Science, Penzberg, Germany) according to the manufacturer's instructions. Briefly, $1 \mathrm{ml}$ cardiomyocyte suspension $\left(1 \times 10^{4}\right.$ cells $)$ was centrifuged at $300 \mathrm{~g}$ for $5 \mathrm{~min}$. The resultant cell pellet was incubated in $200 \mu \mathrm{l}$ lysis buffer for $30 \mathrm{~min}$ at room temperature and centrifuged at $300 \mathrm{~g}$ for $5 \mathrm{~min}$. Then $20 \mu \mathrm{l}$ resultant supernatant containing cytoplasmic histone-associated DNA fragments was added to a streptavidincoated microtitre plate, followed by $80 \mu \mathrm{l}$ immunoreagent containing anti-histone biotin against histone and anti DNA-peroxidase against DNA to each well. The plate was shaken gently $(300 \mathrm{rpm})$ for $2 \mathrm{~h}$ at $15-25^{\circ} \mathrm{C}$ and the unbound antibodies removed by washing the plate three times with $250 \mu$ incubation buffer. ABTS (2,2'-azino-di-(3-ethylbenzthiazolin-sulfonate); $100 \mu \mathrm{l})$ reagent was added as a substrate and the fluorescence was measured, using a microtitre plate reader, at emission wavelength of $450 \mathrm{~nm}$ with $490 \mathrm{~nm}$ as reference wavelength. Data in both control and experimental groups are presented as difference of absorbance $\left(A_{405 \mathrm{~nm}}-A_{490 \mathrm{~nm}}\right)$ wavelength.

\section{Statistical analysis}

All values are expressed as means with their standard errors. Differences between two groups were evaluated by Student's $t$ test. Data from more than two groups were evaluated by oneway ANOVA with the Bonferroni post hoc test for multiple comparisons. To exclude the possibility of litter effects within the two groups, the data at each time point for each group were evaluated 
by two-way ANOVA. A probability of $95 \%$ or more $(P<0.05)$ was considered significant.

\section{Results}

\section{General characteristics of experimental animals}

The energy and food intake of the pregnant rats fed 18 and $9 \%$ casein diets did not differ significantly, although a $44 \%$ reduction in protein intake of the group fed $9 \%$ casein relative to the control group fed $18 \%$ casein was calculated (Table 2). Although pups born to the dams fed the LP diet were significantly lighter (Table 2), the rate of growth, as determined by body weight gain during weeks 2 to 8 , was greater in the LP-exposed animals $(25.0 \mathrm{~g} / \mathrm{d}$ LP group $v .17 .4 \mathrm{~g} / \mathrm{d}$ control group). However, from 12 weeks of age, a $42 \%$ decrease in the rate of weight gain $(1.4 \mathrm{~g} / \mathrm{d}$ LP group $v .2 .4 \mathrm{~g} / \mathrm{d}$ control group) was observed (Fig. 1(a)) in the LP group compared with the control.

\section{Cardiac function by echocardiography}

Echocardiography of the hearts of offspring from $24 \mathrm{~h}$ to 40 weeks of age revealed that, when the dams consumed the LP diet during pregnancy, there was a severe depression in the EF of the pups in the first 2 weeks of life with the peak depression at $7 \mathrm{~d}$. This was followed by a recovery and no apparent differences in the EF of the offspring up to 40 weeks of age (Fig. 1(b)).

\section{Cardiomyocyte apoptosis}

Direct evidence for cardiomyocyte apoptosis was obtained by using a cell death ELISA kit. It can be seen from Fig. 2 that there was an age-related increase in apoptosis of the cardiomyocytes in the LP-exposed group compared with the control group. An almost three-fold increase in cardiomyocyte apoptosis was seen at $5 \mathrm{~d}$ of age in the LP group.

Left ventricular functional assessment by in vivo catheterization technique

Catheterization assessment of LV function at 40 weeks of age showed the occurrence of LV hypertrophy (20\%), a two-fold

Table 2. Maternal body weight, energy and food intake and birth weight of male offspring

(Values are means and standard errors of five observations in each dietary group for maternal body weight, energy intake and food intake, and of fifteen measurements in each dietary group for offspring birth weight)

\begin{tabular}{|c|c|c|c|c|}
\hline & \multicolumn{2}{|c|}{$\begin{array}{l}\text { Control } \\
\text { (18\% protein) }\end{array}$} & \multicolumn{2}{|c|}{$\begin{array}{l}\text { Low protein } \\
\text { (9\% protein) }\end{array}$} \\
\hline & Mean & SE & Mean & SE \\
\hline Protein intake (\% of control) & 100 & - & 56 & 3 \\
\hline \multicolumn{5}{|l|}{ Maternal body weight $(\mathrm{g})$} \\
\hline Pre-pregnancy & 247 & 12 & 253 & 14 \\
\hline Mating & 264 & 11 & 259 & 17 \\
\hline Final & 388 & 19 & 367 & 21 \\
\hline Maternal energy intake $(\mathrm{kJ} / \mathrm{d})$ & 564 & 22 & 546 & 22 \\
\hline Maternal food intake $(\mathrm{g} / \mathrm{d})$ & 28.5 & 3.5 & $25 \cdot 0$ & $4 \cdot 0$ \\
\hline Offspring birth weight $(\mathrm{g})$ & 5.44 & 0.07 & 4.24 & $0.07^{\prime}$ \\
\hline
\end{tabular}

Mean values were significantly different from those of the control $(18 \mathrm{~g}$ casein $/ \mathrm{g}$ diet) group: ${ }^{*} P<0.05$. elevation of LV end-diastolic pressure, a $54 \%$ reduction in cardiac output and a loss of $\mathrm{LV}$ function $\left(+\mathrm{d} P / \mathrm{d} t_{\max }\right.$ and $\left.-\mathrm{d} P / \mathrm{d} t_{\max }\right)$ in the LP-exposed group. The systolic pressure was not significantly different between the experimental groups; however, an approximate $50 \%$ fall in diastolic pressure as well as a decrease in mean arterial pressure was seen in the LP group. In addition, the pulse pressure was increased significantly in the LP-exposed group (Table 3).

\section{Morphological changes of the heart}

The LV internal diameters during systole and diastole were increased between $24 \mathrm{~h}$ and $84 \mathrm{~d}$ (12 weeks) of age in the LPexposed group; however, no differences between the control and LP groups were seen after this age (Figs 3(a) and 3(b)). To understand the nature of these changes, the LV wall thickness as a function of age was also determined in these experimental groups. Figs 4(a) and 4(b) show that, between $3 \mathrm{~d}$ and 2 weeks of age, the LV wall of the heart in the LP group was thinner
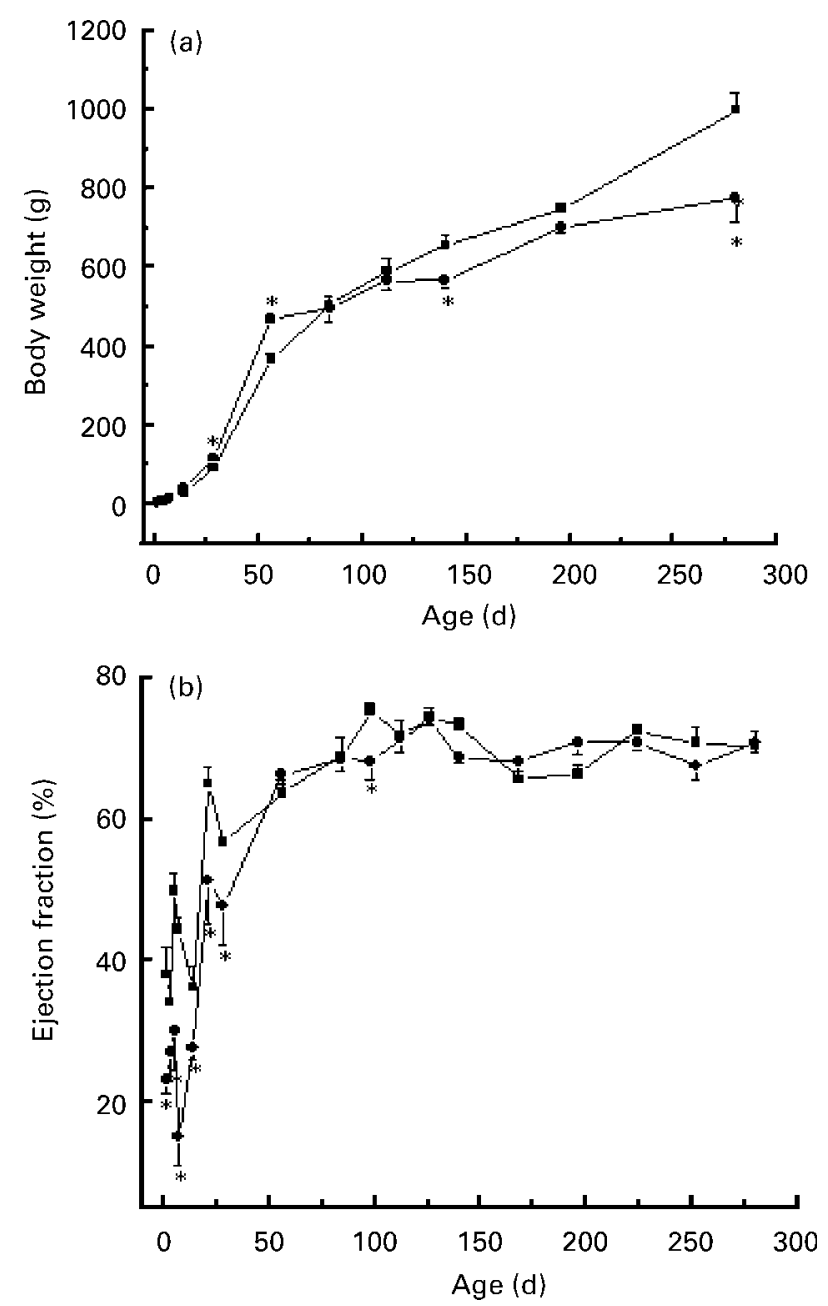

Fig. 1. Age-related changes in body weight (a) and ejection fraction (b) of male offspring exposed to a low-protein diet $(\bullet)$ in utero, compared with controls $(\boldsymbol{\square})$. Echocardiography, using an ultrasound imaging system, was used for measurement of the ejection fraction of the hearts of male offspring (at $24 \mathrm{~h}$ and up to 40 weeks of age), as described on p. 472 . Values are means with standard errors shown by vertical bars for fifteen animals in each group (three pups per dam; five dams each in control and low-protein group). Mean values were significantly different from those of the control $(18 \mathrm{~g}$ casein $/ \mathrm{g}$ diet) group: ${ }^{*} P<0.05$. 


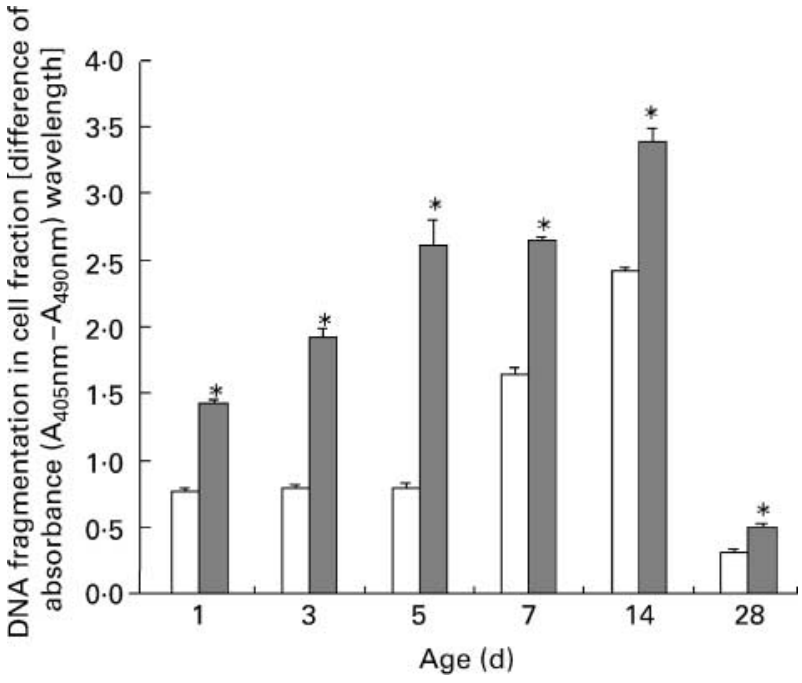

Fig. 2. Cardiomyocyte apoptosis in male offspring exposed to a maternal low-protein diet $(\square)$ in utero, compared with controls $(\square)$. A single neonatal cardiomyocyte preparation was isolated by collagenase digestion, at each of the time points, from four to six male pups per dam from control and low-protein groups, as described on p. 472. Values are means with standard errors shown by vertical bars of three independent measurements, conducted in triplicate, with three different cell preparations. Mean values were significantly different from those of the control ( $18 \mathrm{~g}$ casein $/ \mathrm{g}$ diet) group: ${ }^{*} P<0.05$.

(as indicated by the shorter wall thickness in systole and diastole) compared with controls; after which time there was a progressive increase in LV wall thickness in this group.

\section{Discussion}

A number of studies investigating the role of postnatal nutrition and CVD have been conducted; however, virtually nothing is known about the effects of prenatal nutrition and risk of primary heart disease in adult life. Although the fetal origins hypothesis has recently received some robust criticism (Lucas et al. 1999; Johansson \& Rasmussen, 2001; Henriksen \& Clausen, 2002; Huxley et al. 2002; Krishnaswamy et al. 2002), both human and animal studies have shown that maternal diet composition during pregnancy programs blood pressure in adolescent and adult life (Langley \& Jackson, 1994; Adair et al. 2001). However, no studies have been conducted to examine if inadequate maternal nutrition during pregnancy predisposes the offspring to cardiac dysfunction in later life. The present study was therefore conducted to test the hypothesis that a maternal LP diet leads to irreversible adaptations in the structure and function of the heart of the developing fetus and predisposes the offspring to the later onset of cardiac abnormalities. In an established rat model of intrauterine growth retardation (Langley \& Jackson, 1994), we are the first to report that a maternal LP diet results in the occurrence of cardiac dysfunction in the offspring in later life and that it is associated with low birth weight.

A severe depression in the EF of the pups in the first 2 weeks of life, with a nadir at $7 \mathrm{~d}$, was followed by recovery and no differences in the EF of the offspring up to 40 weeks of age. Although the LV internal diameters during systole and diastole were increased between $24 \mathrm{~h}$ and $84 \mathrm{~d}$ of age in the LP-exposed group, the assessment of LV wall thickness revealed an early thinning of the wall followed by a progressive thickening of the wall. These observations provided evidence that cardiomyocytes of the hearts of animals of the LP group underwent initial eccentric hypertrophy and a later concentric hypertrophy. Our findings would suggest that the eccentric hypertrophy in the LP group is in response to the marked reduction in $\mathrm{EF}$ as a result of a severe loss in cardiomyocytes due to an increase in apoptosis. The response of the heart to poor contractility is to undergo compensatory changes and such LV remodelling (LV dilation and LV

Table 3. General characteristics and left ventricular function of male offspring exposed to a low-protein diet in utero, compared with controls

(Values are means and standard errors of fifteen different animals in each group: three pups per dam; five dams each in control and low-protein group)

\begin{tabular}{|c|c|c|c|c|}
\hline \multirow[b]{2}{*}{ Parameter } & \multicolumn{2}{|c|}{ Control (18\% protein) } & \multicolumn{2}{|c|}{ Low protein ( $9 \%$ protein) } \\
\hline & Mean & SE & Mean & SE \\
\hline Body weight (g) & 779 & 17 & 671 & $20^{*}$ \\
\hline LV weight (mg) & 1114 & 30 & 1190 & $15^{\star}$ \\
\hline LV weight:body weight $(\mathrm{mg} / \mathrm{g})$ & 1.5 & 0.04 & $1 \cdot 8$ & $0.05^{*}$ \\
\hline LVEDP $(\mathrm{mmHg})$ & $6 \cdot 67$ & 0.35 & $12 \cdot 5$ & $0.32^{*}$ \\
\hline $\operatorname{LVSP}(\mathrm{mmHg})$ & 109 & 11 & 101 & 8 \\
\hline$+\mathrm{d} P / \mathrm{d} t_{\max }(\mathrm{mmHg} / \mathrm{s})$ & 3821 & 564 & 2615 & $391^{*}$ \\
\hline$-\mathrm{d} P / \mathrm{d} t_{\max }(\mathrm{mmHg} / \mathrm{s})$ & 3035 & 431 & 2331 & $164^{\star}$ \\
\hline $\mathrm{SP}(\mathrm{mmHg})$ & 117 & 9 & 95 & 6 \\
\hline $\mathrm{DP}(\mathrm{mmHg})$ & 73 & 9 & 38 & $3^{*}$ \\
\hline $\operatorname{MAP}(\mathrm{mmHg})$ & 88 & 8 & 57 & $3^{*}$ \\
\hline $\mathrm{PP}(\mathrm{mmHg})$ & 44 & 5 & 57 & $3^{*}$ \\
\hline $\mathrm{CO}(1 / \mathrm{min})$ & 0.059 & 0.003 & 0.027 & 0.004 \\
\hline Heart rate (beats/min) & 345 & 26 & 340 & 30 \\
\hline
\end{tabular}

The left ventricular (LV) weight of the experimental animals refers to the weight of the left ventricle plus septum. The in vivo catheterization technique was used for the measurement of LV end-diastolic pressure (LVEDP), LV systolic pressure (LVSP), maximum rate of contraction $\left(+\mathrm{d} P / \mathrm{d} t_{\text {max }}\right)$, maximum rate of relaxation $\left(-\mathrm{d} P / \mathrm{d} t_{\max }\right)$, systolic pressure (SP), diastolic pressure (DP), mean arterial pressure (MAP), pulse pressure (PP) and cardiac output (CO). Haemodynamic data were computed as described on p. 472

Mean values were significantly different from those of the control (18 g casein/g diet) group: ${ }^{*} P<0.05$. 

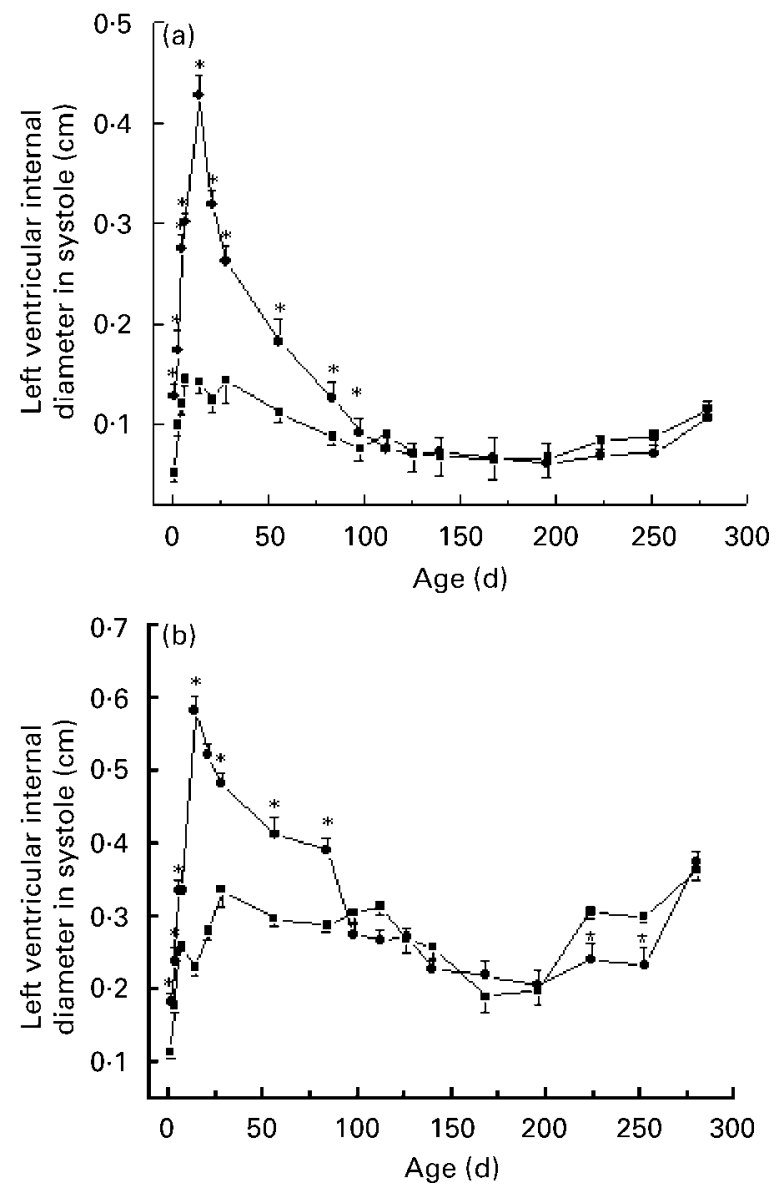

Fig. 3. Changes in cardiac left ventricular internal diameter of male offspring of dams fed a low-protein diet $(\bullet)$ during pregnancy, compared with controls (ם). M-mode images of the left ventricular internal diameter during systole (a) and diastole (b) of hearts of male offspring (at $24 \mathrm{~h}$ and up to 40 weeks of age) were obtained by echocardiography, using an ultrasound imaging system as described on p. 472. Values are means with standard errors shown by vertical bars for fifteen animals in each group (three pups per dam; five dams each in control and low-protein group). Mean values were significantly different from those of the control ( $18 \mathrm{~g}$ casein $/ \mathrm{g}$ diet) group: ${ }^{*} P<0.05$.

shape changes) is considered an important component in the evolution of heart failure (Sabbah, 2003; Udelson et al. 2003). The early occurrence of LV remodelling in the hearts of the LP group predisposes this group to later LV dysfunction.

Although echocardiography revealed that the EF was normal in the LP group, in vivo assessment of haemodynamic function of the experimental animals at 40 weeks of age revealed a twofold elevation of the LV end-diastolic pressure and a reduction in diastolic function (decrease in $-\mathrm{d} P / \mathrm{d} t$ ) of the LP group. However, the catheterization technique also revealed systolic dysfunction in the LP group. In this regard, in patients with a normal or nearly normal EF, it is assumed that since there is a 'preserved systolic function' the primary disorder is diastolic. Although the $\mathrm{EF}$ assesses global function, it is a relatively crude measure of LV systolic function, and measurement of the ventricular longaxis velocities and amplitude using tissue Doppler and M-mode imaging of the mitral annulus is thought to provide a more sensitive index of systolic function than EF (Henein, 1999). In fact, such measurements have been conducted in patients having diastolic heart failure with evidence of LV hypertrophy and normal $\mathrm{EF}$, and they have been found to exhibit systolic LV impairment (a)

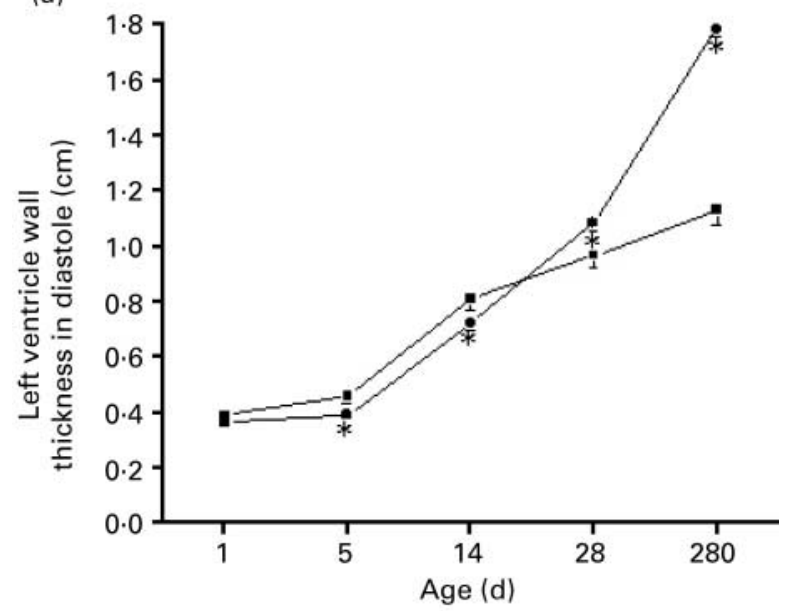

(b)

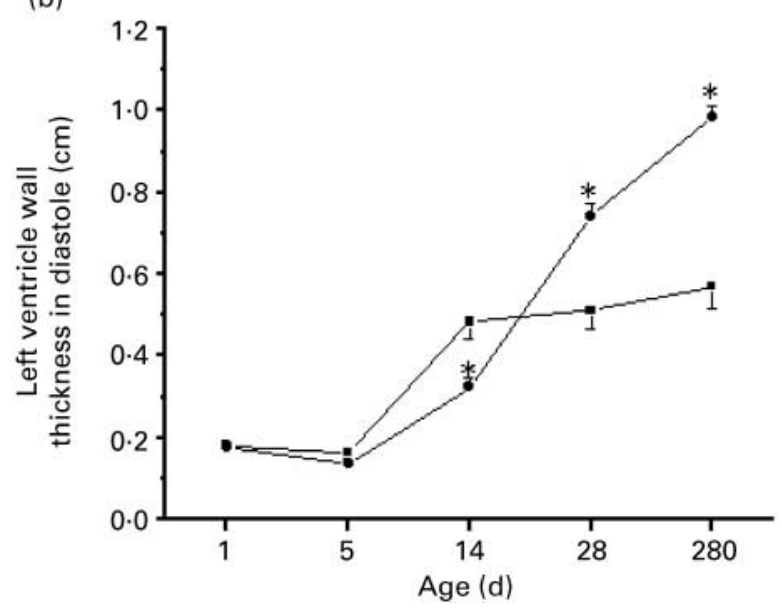

Fig. 4. Left ventricle wall thickness of hearts of male offspring exposed to a maternal low-protein diet $(\bullet)$ in utero, compared with controls (ם). M-mode images of the left ventricular wall thickness during systole (a) and diastole (b) of hearts of male offspring (at $24 \mathrm{~h}$ and up to 40 weeks of age) were obtained by echocardiography, using an ultrasound imaging system as described on p. 472. Values are means with standard errors shown by vertical bars for fifteen animals in each group (three pups per dam; five dams each in control and low-protein group). Mean values were significantly different from those of the control ( $18 \mathrm{~g}$ casein/g diet) group: ${ }^{\star} P<0.05$.

(Yip et al. 2002), which is in accordance with our findings. A $13 \mathrm{mmHg}$ increase in pulse pressure was also seen in the LP group due to the marked decrease in diastolic pressure, providing further evidence of the occurrence of diastolic abnormalities in the LP group. Taken together, our data represent the progression of hypertrophy and structural remodelling to diastolic and systolic dysfunction in the LP group and it is conceivable that, beyond 40 weeks of age, this series of events could progress to diastolic and systolic heart failure and may end with sudden cardiac death or intractable end-stage failure (Mandinov et al. 2000). It is pointed out that while the cardiac functional data presented in the present paper are for male offspring, similar observations for female offspring were also recorded (data not shown).

While others have reported an elevation in systolic blood pressure in offspring in this model (Langley \& Jackson, 1994), at least up to 21 weeks of age, we did not see an increase in systolic blood pressure in the LP group at 40 weeks of age. In this regard, consistent with the 
findings of others (Langley \& Jackson, 1994; Langley-Evans et al. 1996), an elevation of systolic blood pressure using tail cuff plethysmography (in the same rats that also underwent cardiac catheterization) was recorded in the LP group at 4 weeks of age (108 (SE 6) $\mathrm{mmHg}$ in control v. 136 (SE 8) $\mathrm{mmHg}$ in the LP group; fifteen different animals in each group: three pups per dam, five dams each in control and LP group). At 12 weeks of age, the systolic blood pressure remained elevated (118 (SE 8) mmHg in control v. 147 (SE 9) $\mathrm{mmHg}$ in the LP group; fifteen different animals in each group: three pups per dam, five dams each in control and LP group). However, at 40 weeks of age, although we did not employ tail cuff plethysmography for the measurement of systolic blood pressure, according to the parameters measured by the in vivo catheterization technique there were no differences in the systolic blood pressure between the groups. This is borne out from the observation that the systolic pressure (and LV systolic pressure), which is an indicator of the peripheral resistance, was not statistically different between the groups, although the mean values for these measurements were lower in the LP group. While our findings are suggestive of a fall in systolic blood pressure in the LP group at 40 weeks of age, as compared with systolic blood pressure at 12 weeks of age, this important observation needs to be confirmed by telemetric tracking of systolic blood pressure over time to establish the biphasic nature of the systolic blood pressure changes in the LP group. Nevertheless, this apparent time-dependent drop in systolic blood pressure is most likely due to the impaired LV systolic function.

While temporal measurements of cardiac function were made using echocardiography, a limitation of our work is that cardiac function measurements in catheterized rats were made only at 40 weeks of age and thus the onset of the deterioration of cardiac function remains to be established. Furthermore, whether the severity of cardiac dysfunction worsens progressively is also a matter to be explored. On this note, it is known that the ageing process is a major factor that contributes to changes in the cardiovascular system seen in older people (Oxenham \& Sharpe, 2003). Catch-up growth is due to accelerated shortening of chromosomal telomeres as a result of increased cell division and could lead to cell senescence in critical organs (Jennings et al. 1999), possibly including the heart. On the basis of our findings, it is conceivable that cardiac dysfunction in the LP-exposed group may be due to an early ageing effect in the heart.

Although the synthetic LP diet had the same energy content as the control diet, a contribution to cardiac dysfunction induced by an increase in the intake of alternative sources of energy cannot be excluded. Nevertheless, our data have provided evidence that exposure of the developing fetus to a maternal LP diet during pregnancy results in structural and functional adaptations that predispose the offspring to the occurrence of an impaired diastolic function, which is independent of the peripheral resistance, and the occurrence of systolic dysfunction in later life, and may represent the early stages of the syndrome of congestive heart failure. It should be noted that mitosis of cardiomyocytes in the human and rat heart is the same, and division of these cells occurs mostly in the first trimester and declines progressively to very low levels in late fetal and early postnatal life (Erokhina et al. 2000). Our findings suggest that the programming of the heart resulting in structural and functional changes covers the time of maximal cardiomyocyte proliferation/differentiation, and although our study examined the effects of the maternal LP diet throughout the gestation period, there is the possibility that a maternal LP diet could have different outcomes for the heart depending on the timing of the insult during pregnancy. In this regard, animal studies have shown that exposure to LP diets during discrete periods of gestation result in differing severity of hypertension (Langley-Evans et al. 1996). Specifically, a greater effect was seen with maternal undernutrition in mid to late gestation, although the systolic blood pressure increases elicited by these discrete periods of undernutrition were lower than those induced by feeding a LP diet throughout pregnancy.

Future studies will now be undertaken to determine the factors involved in the pathophysiological events leading to cardiomyocyte dysfunction in animals exposed to a LP diet in utero. Candidates for investigation include elevations in angiotensin II signalling, alterations in NO signalling and/or enhanced $\beta$-adrenergic signalling, and changes in the collagen matrix and contractile protein profile or changes in the excitation-contraction coupling.

\section{Acknowledgement}

This study was supported by a grant from the Manitoba Medical Service Foundation.

\section{References}

Adair LS, Kuzawa CW \& Borja J (2001) Maternal energy stores and diet composition during pregnancy program adolescent blood pressure. Circulation 104, 1034-1039.

Aihie Sayer A, Dunn R, Langley-Evans SC \& Cooper C (2001) Prenatal exposure to a maternal low protein diet shortens life span in rats. Gerontology 47, 9-14.

Al-Ghazali W, Cita SK, Chapman MG \& Allan LD (1989) Evidence of redistribution of cardiac output in asymmetrical growth retardation. Br J Obstet Gynaecol 96, 697-704.

Barker DJP (1997) Fetal nutrition and cardiovascular disease in later life. Br Med Bull 53, 96-108.

Barker DJP, Eriksson JG, Forsen T \& Osmond C (2002) Fetal origins of adult disease: strength of effects and biological basis. Int J Epidemiol 31, 1235-1239.

Cianfarani S, Germani D \& Branca F (1999) Low birthweight and adult insulin resistance: the 'catch-up growth' hypothesis. Arch Dis Child Fetal Neonatal Ed 81, F71-F73.

Erokhina IL, Selivanova GV, Vlasova TD, Emel'ianova OI \& Lagutenko OI (2000) Mitotic activity, ploidy and ultrastructure of cardiomyocytes from human embryo and fetuses. Tsitologiia 42, 146-153.

Fall CHD, Osmond C, Barker DJP, Clark PM, Hales CN, Stirling Y \& Meade TW (1995) Fetal and infant growth and cardiovascular risk factors in women. Br Med J 310, 428-432.

Godfrey KM, Barker DJ, Robinson S \& Osmond C (1997) Maternal birthweight and diet in pregnancy in relation to the infant's thinness at birth. Br J Obstet Gynaecol 104, 663-667.

Henein MY (1999) Long axis function in disease. Heart 81, 229-231.

Henriksen T \& Clausen T (2002) The fetal origins hypothesis: placental insufficiency and inheritance versus maternal malnutrition in well-nourished populations. Acta Obstet Gynecol Scand 81, 112-116.

Huxley R, Neil A \& Collins R (2002) Unravelling the fetal origins hypothesis: is there really an inverse association between birthweight and subsequent blood pressure? Lancet 360, 659-665.

Jennings BJ, Ozanne SE, Dorling MW \& Hales CN (1999) Early growth determines longevity in male rats and may be related to telomere shortening in the kidney. FEBS Lett 448, 4-8.

Johansson M \& Rasmussen F (2001) Birthweight and body mass index in young adulthood: the Swedish young male twins study. Twin Res $\mathbf{4}$, 400-405.

Krishnaswamy K, Naidu AN, Prasad MP \& Reddy GA (2002) Fetal nutrition and adult chronic disease. Nutr Rev 60, S35-S39. 
Langley SC \& Jackson AA (1994) Increased systolic blood pressure in adult rats induced by fetal exposure to maternal low protein diets. Clin Sci 86, 217-222.

Langley-Evans SC, Welham SJ, Sherman RC \& Jackson AA (1996) Weanling rats exposed to maternal low-protein diets during discrete periods of gestation exhibit differing severity of hypertension. Clin Sci 91, 607-615.

Lucas A, Fewtrell MS \& Cole TJ (1999) Fetal origins of adult disease the hypothesis revisited. Br Med J 319, 245-249.

Malhotra R \& Brosius FC III (1999) Glucose uptake and glycolysis reduce hypoxia-induced apoptosis in cultured neonatal rat cardiac myocytes. $J$ Biol Chem 274, 12567-12575.

Mandinov L, Eberli FR, Seiler C \& Hess OM (2000) Diastolic heart failure. Cardiovasc Res 45, 813-825.

Oxenham H \& Sharpe N (2003) Cardiovascular aging and heart failure. Eur J Heart Fail 5, 427-434.

Rizzo G \& Arduini D (1991) Fetal cardiac function in intrauterine growth retardation. Am J Obstet Gynecol 165, 876-882.

Sabbah HN (2003) The cardiac support device and the myosplint: treating heart failure by targeting left ventricular size and shape. Ann Thorac Surg 75, S13-S19.

Severi FM, Rizzo G, Bocchi C, D’Antona D, Verzuri MS \& Arduini D (2000) Intrauterine growth retardation and fetal cardiac function. Fetal Diagn Ther 15, 8-19.
Tappia PS, Liu S-Y, Shatadal S, Takeda N, Dhalla NS \& Panagia V (1999) Changes in sarcolemmal PLC isoenzymes in postinfarct congestive heart failure: partial correction by imidapril. Am J Physiol 277, H40-H49.

Udelson JE, Patten RD \& Konstam MA (2003) New concepts in post-infarction ventricular remodelling. Rev Cardiovasc Med $\mathbf{4}$ S3-S12.

Veille JC, Hanson R, Sivakoff M, Hoen H \& Ben-Ami M (1993) Fetal cardiac size in normal, intrauterine growth retarded, and diabetic pregnancies. Am J Perinatol 10, 275-279.

Vijayakumar M, Fall CH, Osmond C \& Barker DJP (1995) Birth weight, weight at one year and left ventricular mass in adult life. Br Heart J 73, $363-367$.

Vonnahme KA, Hess BW, Hansen TR, et al. (2003) Maternal undernutrition from early- to mid-gestation leads to growth retardation, cardiac ventricular hypertrophy and increase liver weight in the fetal sheep. Biol Reprod 69, 133-140.

Yang X-P, Liu Y-H, Rhaleb N-E, Kurihara N, Kim HE \& Carretero OA (1999) Echocardiographic assessment of cardiac function in conscious and anesthetized mice. Am J Physiol 277, H1967-H1974.

Yip G, Wang M, Zhang Y, Fung JWH, Ho PY \& Sanderson JE (2002) Left ventricular long axis function in diastolic heart failure is reduced in both diastole and systole: time for a redefinition? Heart 87, 121-125. 